International Journal of Innovation Management

Vol. 23, No. 1 (January 2019) 1950002 (33 pages)

(C) World Scientific Publishing Europe Ltd.

DOI: $10.1142 /$ S1363919619500026

\title{
WHAT DOES OPEN INNOVATION MEAN? BUSINESS VERSUS ACADEMIC PERCEPTIONS
}

\author{
ROMAN TEPLOV* \\ Lappeenranta University of Technology \\ School of Business and Management \\ P.O. Box 20, Lappeenranta 53851, Finland \\ roman.teplov@lut.fi \\ EKATERINA ALBATS ${ }^{* \dagger}$ and DARIA PODMETINA** \\ Lappeenranta University of Technology \\ School of Business and Management \\ Kouvola Unit, Prikaatintie 9, FI-45100 Kouvola, Finland \\ †ekaterina.albats@lut.fi \\ daria.podmetina@lut.fi
}

Published 9 April 2018

\begin{abstract}
Since the first appearance of 'open innovation' as a theoretical concept in 2003, the debates on its essence still continue among academics, while its interpretations within the business community also seem to differ from one company to another. Using a survey of 251 companies operating in Europe, in this research, we compare the perceptions of open innovation that exist within both the academic and business worlds, to assist in the conceptual development of the phenomenon. Our research reveals a mismatch in these perceptions, as only a few activities counted as 'open' by innovation scholars appear to affect companies' self-reported state of open innovation implementation. Moreover, our research has shown differences in the interpretation of open innovation among companies of different sizes. Only free revealing, acknowledged by scholars as one of the open innovation practices, has been recognised as such a practice by all the studied firms. This paper contributes to conceptualisation of 'open innovation' and shares practical insights on bridging academia and business perceptions of it.
\end{abstract}

Keywords: Open innovation; open innovation definition; academic perception of open innovation; business perception of open innovation; open innovation activity; open innovation in Europe; open innovation self-perception; survey; quantitative research.

\footnotetext{
*All authors contributed equally.

${ }^{\ddagger}$ Corresponding author.
} 


\section{Introduction}

Academic journal publications, practice-oriented books, and business cases have provided an enormous number of definitions of open innovation (OI) and a variety of firms' activities associated with OI (Chesbrough and Bogers, 2014; Dahlander and Gann, 2010; Greco et al., 2015; Remneland-Wikhamn and Wikhamn, 2013). OI has rapidly gained great popularity both as a 'trendy' managerial approach within the business community and as a theoretical concept intensively studied by business scholars. However, around the glorious story of 'open innovation', there is some criticism of its doubtful newness and, furthermore, confusion over what is perceived to be behind these two 'magic' words - both between and within the business and scientific communities.

The first critical notion regarding the concept of OI raised the idea that most of 'so called' OI practices were applied by companies long before the time when the term was introduced (Trott and Hartmann, 2009; Oakey, 2013). The weaknesses and limitations of OI are also heavily criticised by the academic community (Piller and Walcher, 2006; Trott and Hartmann, 2009; Dahlander and Gann, 2010; Knudsen and Mortensen, 2011). Such criticism is, in fact, a natural process of theory development (Popper, 1994). Furthermore, even OI scholars express their concern about the conceptual ambiguity of OI, which brings us back to the problems of the different understanding of OI in business and academia.

Thus, the problem of conceptual ambiguity around 'open innovation' (Trott and Hartmann, 2009) could not yet be solved simply by academic researchers clarifying and describing their vision of OI as the roots of the problem lie deeply along the rigour-relevance debate in management research (Gulati, 2007). In this respect, Groen and Linton (2010) legitimately stress the relevance of the 'open innovation' concept per se, and particularly, in respect to its overlap or its certain complementarity with the term of 'supply chain', where different actors along the supply chain or various company stakeholders (Freeman et al., 2010) create value jointly. In response to this strong and relevant argument, van de Vrande and Man (2011) make a stand for 'open innovation' as it 'cuts across various existing research domains and therefore may help to integrate them' (p. 186). However, in the same discussion note, van de Vrande and Man (2011) heavily stress the issue of the relevance of general managerial research (in respect to 'open innovation' relevance) for practitioners. They confirm the lack of such relevance together with a desperate need for the 'new theoretical lens, grounded in practical problems, that supersedes the pre-existing individual lenses' and suggest that 'the core problem ... should be solved by focusing our research more on integrative, practical problems...' (van de Vrande and Man, 2011, p. 186). Among a few recipes for achieving rigour and relevance while developing a new theory (as the scholars 
currently do in the OI landscape), Gulati (2007, p. 780) proposes scholars to 'appreciate and synthesize the dialectic between theory and phenomenon'. That is why we claim that it is critically needed to examine the relevance of 'open innovation as a concept,' for 'open innovation as a phenomenon' - compare the perceptions of OI among scholars and practitioners - in order to improve the rigour and relevance of $\mathrm{OI}$ as a theoretical lens in management research.

The researchers analyse the variables reflecting companies' activities perceived as 'open' by the academic literature, and the measurements are proposed and validated by, again, the researchers (see, e.g., Chesbrough and Brunswicker, 2014). However, in practice, companies might have a different view of their operations. Thus, the companies' actual activities need to be assessed against, first, the practices acknowledged as 'open innovation' in the academic literature, and second, the companies' own perception of such practices. OI suffers from a lack of sufficient methodology and measurement instruments (Podmetina et al., 2014), and this limitation requires contributions from both the practical and academic sides. The extensive usage of the OI concept has led to a very diverse interpretation of it within academic versus business communities. Thus, the question remains 'what should be counted as open innovation and what should not be?'.

Trying to answer this question, we first measure the activities that companies apply in practice: 'what companies $d o$ '. We asked firms to specify whether they adopt (and if yes, then how intensively) the activities acknowledged as 'open innovation' activities by the literature. The list of these 13 activities (elaborated based on the academic literature) was provided in the questionnaire. Then, we analyse companies' own perceptions of their OI adoption, aiming to understand 'what companies think they do'. We asked firms to choose, from the offered list, the stage of their firm's OI adoption, from 'not implementing open innovation, and not planning to implement' to 'experienced adopters of open innovation' (see the table on operationalization of variables for further details).

Based on these concepts and the identified research gap, we formulated our research questions as follows:

1. How does actual OI adoption vary between companies who claim to be OI adopters, and those who claim that they do not adopt OI?

2. What OI activities, identified as such by academic researchers, are not considered 'open' by business practitioners?

The paper is structured as follows: in the literature review, we go through OI definitions and classifications, and the measurement of OI activities, as proposed in the academic literature, and we look for existing confusion and inconsistencies. We also analyse the perception of OI in companies, as presented in business cases. 
The methodology section explains our data collection process, sampling, and methods of analysis. Then we present and discuss our results. In the conclusion, we summarise our findings and propose directions for future research.

\section{Perceptions of Open Innovation in Academia and in Business}

The history of the concept of OI started with a book by Chesbrough and several case studies (Chesbrough, 2003a,b, 2004). Gassmann and Enkel conducted the first empirical study on OI in 2004. Since 2006, the number of publications on OI has increased significantly (Chesbrough and Bogers, 2014) and crossed the 500-article threshold in 2013 (Podmetina et al., 2014). By this time, the research on OI had passed through several stages: from the initial theory building, conceptualisation, and development of the methodological instruments (2003-2006); through exploring the concept using qualitative methods, case studies, and first attempts to quantify OI research (2007-2008); to numerous quantitative studies, large-scale surveys, and the application of novel research methods (2009-2013) (Podmetina et al., 2014). Since then, we have been able to observe the new waves of empirical research and case studies, clarifying the main OI components and developing the new applications of the OI paradigm. In this literature review, we go through the perception of the concept of OI reflected in the academic research, as well as in the practitioner-oriented literature, and analyse the confusion and debates that have arisen around this concept.

\section{Definitions of open innovation - an overview}

The interest in OI in the research community has led to the rapid emergence of studies aiming to frame and conceptualise the phenomenon. The first definition of OI by Chesbrough says 'Open innovation is a paradigm that assumes that firms can and should use external ideas as well as internal ideas, and internal and external paths to market, as the firms look to advance their technology' (Chesbrough, 2003a, p. xxiv). West and Gallagher (2006) later gave another wording to OI as '(...) encouraging and exploring a wide range of internal and external sources for innovation opportunities, consciously integrating that exploration with firm capabilities and resources, and broadly exploiting those opportunities through multiple channels' (West and Gallagher, 2006, p. 1).

In 2006, Chesbrough defined OI as 'the use of purposive inflows and outflows of knowledge to accelerate internal innovation, and expand the markets for external use of innovation, respectively'. Since then, there have been many 
attempts to define a firm's openness (e.g., Dahlander and Gann, 2010; Van de Vrande et al., 2010), with an emphasis both on external sources of innovation (Laursen and Salter, 2006) and previously hidden internal ideas (Henkel, 2006). According to Henkel (2006), OI is similar to the phenomenon of collective invention' associated with user innovation.

Contradictory to OI proponents, several authors (e.g., Dahlander and Gann, 2010; Groen and Linton, 2010; Oakey, 2013; Trott and Hartmann, 2009) claim that the concept is not particularly new. They refer to a strong research tradition examining the results of opening up a company's boundaries to the external environment (Freeman, 1974; Pavitt, 1984; von Hippel, 1986; Chandler, 1990). Moreover, they also note a significant overlap between the OI paradigm and the already existing concept of supply-chain management (Mowery, 2009). In response to the criticism, Chesbrough and Bogers (2014, p. 27) give another definition to help in unifying the future work in this area: 'open innovation is a distributed innovation process based on purposively managed knowledge flows across organizational boundaries, using pecuniary and non-pecuniary mechanisms in line with each organization's business model'.

Despite the existence of the well-acknowledged definitions of OI, the 'multidisciplinary origin of the researchers' dealing with OI 'makes it far from easy to form one strong, unified research community which shares one workable, allencompassing definition' and OI 'can be framed in many different - not always congruent - ways' (Remneland-Wikhamn, 2013, p. 386). This broadness of OI concept thus provides additional ground for conceptual ambiguity and the gap in understanding of it by scholars and practitioners.

\section{Classification of open innovation}

Prior research has already pointed out that the ambiguity in OI might cause confusion in companies' understanding of what OI actually is (Dabrowska et al., 2013). Therefore, there is a research gap in structuring OI activities and understanding how companies associate the degree of engagement with the level of OI adoption.

From the academic perspective, Gassmann and Enkel (2004) classified the OI process as the outside-in, the inside-out, and the coupled process. This classification was later applied in research papers by Enkel et al. (2009), Van de Vrande et al. (2009), Rohrbeck et al. (2009), Dahlander and Gann (2010), and others. In 2006, Chesbrough et al. introduced another typology of OI, which is based on 'purposive inflows and outflows of knowledge': inbound and outbound (Chesbrough and Crowther, 2006, p. 1). Inbound OI reflects the outside-in process, and 
outbound OI respectively means the inside-out process. In 2010, the inboundoutbound classification was supplemented with monetary (pecuniary) and nonmonetary (non-pecuniary) dimensions (Dahlander and Gann, 2010). Chesbrough and Brunswicker (2014) later used this matrix for an empirical study in which they also provided a list of inbound and outbound OI activities. In the same year, 2014, Chesbrough and Bogers wrote about OI and "knowledge flows across [an] organizational boundary' (Chesbrough and Bogers, 2014, p. 27), following Gassmann and Enkel's (2004) classification of OI as outside-in (or inbound), inside-out (or outbound), and coupled OI. They also listed the mechanisms that help companies to manage the purposive knowledge flows for each of the OI dimensions.

Respectively, in the age of knowledge-based economy, in the OI processes, there coexist 'knowledge owners/sellers' (which in addition to a business player may be a university or a research institution) and 'knowledge seekers/buyers' as the core actors on the knowledge markets (Natalicchio et al., 2014; Dushnitsky and Klueter, 2017). The actual characteristics of the knowledge-based transactions between the two appear very context-specific due to also the nature of tacit knowledge (Natalicchio et al., 2014; Polanyi, 1966; Nonaka and Takeuchi, 1995). Thus, depending on the contextual settings (which also include environmental ones (Alexy et al., 2009)), the companies adopt various strategies in their OI partnerships from very formal agreements (Gomes et al., 2016) to less formal, trust- or in-kindbased relationships and/or involving intermediaries (Elmquist et al., 2016).

This dualism of the OI nature - inclusion of both pecuniary and non-pecuniary activities, diversity in terms of the relationships formality — reflects 'libre' versus 'control' debate and keeps OI along the entire spectrum, which in turn 'tends to give a somewhat fragmented and incoherent perception of what open innovation is and how it should be applied in practice.' (Remneland-Wikhamn and Wikhamn, 2013, p. 375).

It can be observed from the empirical studies examining OI adoption that companies tend to engage more with inbound rather than outbound activities (e.g., Van der Meer, 2007; Van de Vrande et al., 2009; Schroll and Mild, 2011). Likewise, the academic research pays more attention to inbound rather than outbound or coupled OI (Chesbrough and Bogers, 2014; West and Bogers, 2013). However, the question of what activities practitioners and researchers associate with inbound and outbound and/or coupled OI remains open.

\section{Measurement of OI}

The confusion in the classification of OI activities leads to the other wave of criticism: the separate measurement constructs differently applied by researchers. 
The most commonly used is, perhaps, external ideas and knowledge sourcing and acquisition (proposed by Chesbrough, 2003a). Among the OI measurement instruments, knowledge acquisition refers to the activities when companies seek and acquire technologies from outside (Laursen and Salter, 2006) in order to complement internally developed $R \& D$ and achieve better competitiveness in the market. External technology acquisition is most commonly measured by the level of external knowledge 'breadth' (a combination of 16 sources of knowledge for innovation) and 'depth' ('the extent to which firms draw intensively from different search channels or sources of innovative ideas' (Laursen and Salter, 2006, 134)) (Ebersberger et al., 2012; Köhler et al., 2012; Laursen and Salter, 2006; Sofka and Grimpe, 2010; Spithoven, 2013; Tether and Abdelouahid, 2008, and others).

The study on external knowledge sourcing by Laursen and Salter (2006) has been based on secondary data, and mainly the Community Innovation Survey (CIS). However, CIS was not initially designed to measure OI, which led to the modification of the proposed measures. Thus, Idrissia et al. (2012), in their study on Canadian small- and medium-sized enterprises (SMEs), identify 21 various external knowledge sources instead of the original 16. The application of other secondary sources forces authors to adjust measures for their purposes, and to use proxies (Freitas et al., 2013; Holl and Rama, 2012; Kafouros and Forsans, 2012; Sandulli et al., 2012). The development of an original questionnaire enables the application of more robust indicators specially designed to capture OI adoption, which eventually results in a greater variety of measures aiming to analyse various aspects of OI (e.g., Clausen et al., 2013; Hung and Chou, 2013; RemnelandWikhamn and Wikhamn, 2011; Theyel, 2013).

The use of intellectual property (IP), ideas, and technologies from outside of the company (or an external path to market for internally developed and not used technologies) (Chesbrough, 2006; Gassmann and Enkel, 2004) is still implemented much more rarely than external technology acquisition (Athreye and Cantwell, 2007). Before the introduction of the OI concept, outbound innovation was considered as part of the knowledge transfer phenomenon (Granstrand et al., 1992), as outbound technology transfer. Later, Lichtenthaler (2005, 2007b, 2008a) proposed a measurement for outbound OI, utilising unused technologies within the firm and technology commercialisation mechanisms. This activity, circumventing the Not-Sold-Here syndrome (Herzog, 2011), can be illustrated, for example, by cases of firms aiming for new distribution channels, lower risks, and decreasing R\&D costs, such as IBM and Novartis (Gassmann and Enkel, 2004).

Cooperation in R\&D is widely used as one of the measures of OI (Laursen and Salter, 2006; Spithoven, 2013). Cooperation in innovation and R\&D resulted from a lack of internal resources and has been studied in pre-OI times (Hagedoorn, 2002; De Propris, 2002). There was research on the companies cooperating with 
external partners (Hagedoorn, 2002), learning to integrate external knowledge (Cohen and Levinthal, 1990) and to combine internal and external R\&D in an optimal and risk-free way, making a choice between 'making internally' and 'buying' (Cassiman and Veugelers, 2002).

Chesbrough and Brunswicker in their study (2014) develop and validate a list of OI activities focusing particularly on the large firms. Burcharth et al. (2014) apply a slightly different set of practices in measuring OI in the context of particularly SMEs. Despite the differences brought by the contextual settings, the practices proposed by both studies called for creation of an organisational culture that enables a search for and acquisition of external knowledge. Such a culture in turn helps in overcoming Not-Invented-Here and Not-Shared-Here syndromes (Katz and Allen, 1982; Chesbrough, 2011; Burcharth et al., 2014; Chesbrough and Brunswicker, 2014) and is crucial for OI nowadays (Gassmann et al., 2010).

\section{OI understanding in the business community}

As can be seen in the academic literature, OI as a theoretical concept is still being shaped and developed, and such an evolutionary process also seems to be happening in the business community. If we look at the business-oriented literature, 'open innovation' (as two words used together in the context of strategic innovation development) has already been widely acknowledged by the business community as an integral part of companies' strategic plans, although many problems linked with the related practices remain unsolved (Accenture Survey, 2015; Huston and Sakkab, 2006; Narsalay et al., 2016). However, the perception of OI - the broadness of the term, and the particular company activities that lie behind it - may differ significantly from company to company, as we can see simply by looking at the web pages that describe the role of OI in corporate strategy.

For instance, some of the companies emphasise explicitly the importance of external ideas for their internal competencies and technologies, and, for example, run idea competitions (see AkzoNobel, 2017; Nokia, 2017; Unilever, 2017; Verizon, 2017). In other words, they use the term 'open innovation' predominantly to imply inbound types of OI activities. Such an understanding is well illustrated by an approach towards OI taken by one of the leaders in OI consultancy, NineSigma:

Open Innovation, also known as external or networked innovation, is focused on uncovering new ideas, reducing risk, increasing speed and leveraging scarce resources.... Open Innovation enables a company to connect with someone who has already developed the technology in need or who is further along the development path. (NineSigma, 2017) 
Thus, looking at OI only through the prism of inbound OI, and taking a perspective of benefits for the focal company, reflects a 'take' approach rather than 'give and take', although a financial reward is often to be offered to innovation contributors. Another open innovation incentive for collaborating scientists can be access to 'technologies, services and know-how' and 'a possibility of joint publications in high-profile journals', as mentioned by Astrazeneca (Astrazeneca, 2017). Or, as the 'classical' example of the $P \& G$ Connect and Develop programme (Huston and Sakkab, 2006) suggests, sharing the company's needs helps external parties to discover a path towards joint value creation (P\&G Connect and Develop, 2017).

Some of the companies using a corporate website as their media channel mention OI practices as being those directly associated with the success of their business, and may particularly highlight the role of inbound and outbound practices in their success (see, e.g., Phillips, 2017; Samsung, 2017; and the case of DSM described by Kirschbaum, 2005). Others may also use outbound, non-pecuniary activities as an open-source practice (see IBM, 2017; also described by Chesbrough, 2007), or may diversify the modes of collaboration and the types of collaborating parties when inviting others to collaborate 'openly' (see Bayer, 2017).

As can be seen from an overview of just a few examples from well-known companies, the understanding of OI varies a lot, not only within academia, but also within the business community. In our research, we aim to explore and analyse the patterns existing within both the academic and business worlds, and to compare the two to assist in the conceptual development of the phenomenon.

To summarise, even though, among scholars, there is some degree of agreement about activities related to the OI paradigm, very few researchers have actually made an attempt to systematise and classify such activities and, further, even between those few ones there is a diversity in measuring OI (e.g., Chesbrough and Brunswicker, 2014; Burcharth et al., 2014). Furthermore, it has already been pointed out that the conceptual ambiguity in OI might cause confusion in companies' understanding of what OI actually is. Therefore, there is a research gap in the meticulous classification of OI activities and the understanding of how companies associate the degree of engagement with the level of OI adoption. To address the gap, we propose that there are certain open innovation activities perceived as open innovation ones by academia, but not by businesses/practitioners.

Thus, we propose the following hypothesis: There is at least one open innovation activity perceived as open innovation by academia, but not by businesses/ practitioners.

In other words, we suggest there is at least one OI activity (among 13 activities associated with OI, as derived from the academic literature) that does not have an 
impact on a company's self-identification as an OI adopter. Testing this hypothesis will enable us to understand, firstly, whether the gap between the perceptions of OI adoption actually exists, and secondly, where exactly it lies.

\section{Methodology}

\section{Questionnaire development and operationalization of variables}

This study is a part of a large European project in which one of the aims is to analyse OI adoption in Europe and study the industrial need for OI. This paper is quantitative by nature, and it uses the survey as a research strategy. We developed a questionnaire using the in-depth analysis of the academic literature, consulting and executive reports, and existing questionnaires (e.g., CIS). The structured questions resulted in scales. Some of the variables used in this analysis are summarised in Table 1. The survey questionnaire also included a set of openended questions, and in one of those, we asked our respondents to provide their own definition of OI. It is worth noting that, in the cover letter to the survey, we provided a definition of OI as per Chesbrough (2003a, p. xxiv). However, we still encouraged our respondents to share their own understanding of this phenomenon. Even though it was an optional question, 164 respondents provided their own definition of OI. In order to improve the reliability and validity of the study, we adopted data triangulation and analysed the qualitative answers to enrich the interpretation of the quantitative analysis results.

We used the self-assessed construct of OI status (Table 1) as a dependent variable. The respondents were offered six alternative stages of OI adoption and were asked to choose the most appropriate for their firms. For stage 6, which relates to the companies that 'had OI activities, but decided to discontinue them', we received only one response, therefore we excluded this company from the analysis. The other stages include Stage 1 'We are not adopting and not planning to adopt open innovation'; Stage 2 'We are not currently adopting OI, but plan to implement $\mathrm{OI}$ in the nearest future'; Stage 3 'We are in the early stages of implementing OI activities'; Stage 4 'We are in the process of refining OI activities and shaping programmes to help establish best practices in OI'; and Stage 5 'We are experienced adopters of OI (processes, procedures, and best practices are in place)'.

For the purposes of regression analysis, we recoded the variable into binary form. Category 0 accounts for stages 1 and 2, and represents non-adopters, whereas Category 1 includes stages 3, 4, and 5, and corresponds to adopters of OI.

We used 13 OI activities (Table 1) as independent variables. The actual list of activities has been elaborated based on Chesbrough and Brunswicker (2014). 
What Does Open Innovation Mean?

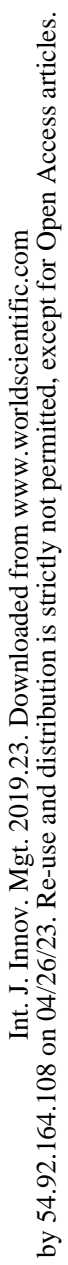

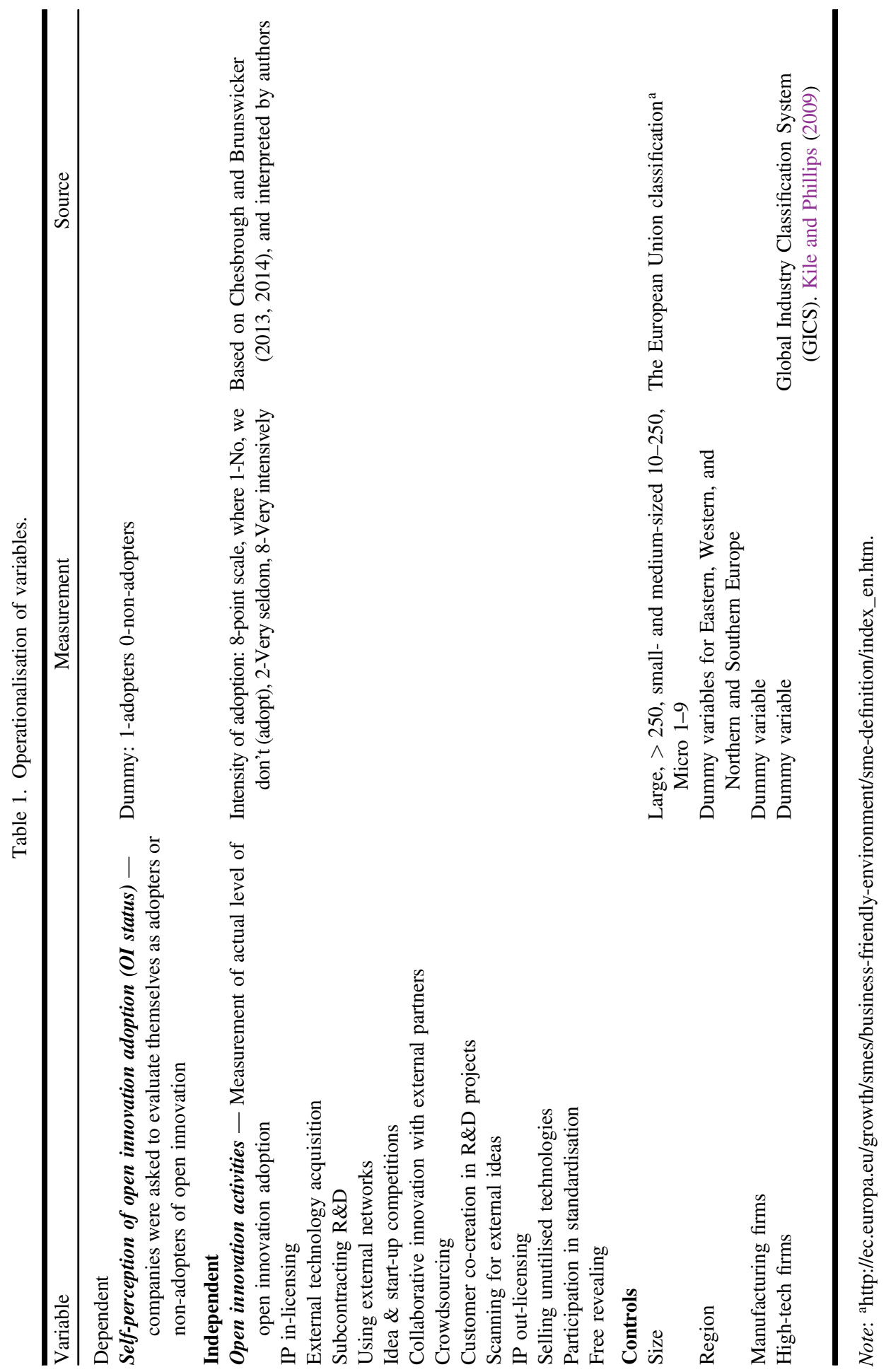


The combined list was subject to evaluation by 50 experts, and the final list after expert evaluation is presented in Table 1. Companies were asked to evaluate the intensity of adoption of each activity using an 8-point scale ranging from one to eight, where one corresponds to non-adoption of the activity, two to very low intensity adoption, and eight means very high intensity of adoption. It is worth noting, that we do not exclude a possibility that the company is an OI adopter even if it does not practice all 13 activities intensively. As mentioned in the title, hence, our intention is to compare self-reported status of OI adoption and their real (actual) understanding of the OI paradigm, its strategy and activities.

We applied company size as a control variable. It was demonstrated by Spithoven et al. (2013) that large and small companies tend to have different approaches to OI. In estimating the company size, the respondents were asked to assign their company to one of four groups, ranging from micro to large, depending on the number of personnel. Then groups of small- and medium-sized firms were merged, to address the EU definition of SMEs (European Commission, 2003). Therefore, in the analysis, we considered large enterprises, SMEs, and microenterprises (see Table 1 for details). Additionally, we controlled for the company's sector (manufacturing vs. services, and high-tech vs. low and medium tech) and region.

\section{Data collection process}

The survey respondents were innovation, $R \& D, H R$, or top managers. As the survey was a part of a large European project aiming to identify industry needs for OI specialists, and the consequent development of the curricula, the inclusion of HR managers in the target respondent group was a necessary prerequisite in order to collect data on the skills and abilities that OI specialists should have (these issues are not within the focus of the current paper, however). We applied the economic significance criteria of the top 5-10 industries in the countries for stratification of the sample. The data were collected using the online survey tool Webropol, between September 2014 and June 2015.

Overall, we received 525 responses to the survey from 38 countries, with an average response rate of $10 \%$ to satisfy the research objectives. The rationale was to focus precisely on private business actors and their understanding of OI. After cleaning the data and removing incomplete questionnaires, we ended up with a sample of 251 firms; this sample was used in further statistical analysis.

The collected sample of European firms presents a particular interest for the study objectives. Although the initial ideas of OI were developed analysing the experience of large multinational companies (though with USA origins) such as 
Table 2. The sample structure.

\begin{tabular}{ll}
\hline Region & $\begin{array}{l}\text { Eastern Europe: } 115(45.8 \%) \text {; Western Europe: } 41(16.3 \%) ; \\
\text { Northern Europe: } 49(19.5 \%) \text {; Southern Europe: } 46(28.3 \%)\end{array}$ \\
Firm size & Large: 98 (39\%); SME: $106(42.2 \%)$; Micro: $47(18.7 \%)$ \\
Industry & High tech: $50(19.9 \%)$ low and medium tech: $202(80.1 \%)$ \\
& Manufacturing: $94(37.8 \%)$; Service: $156(62.2 \%)$ \\
\hline
\end{tabular}

Note: Total sample size, $N=251$.

P\&G, IBM (see e.g., Dodgson et al., 2006; Huston and Sakkab, 2006; Chesbrough, 2007), the consecutive stream of studies was to great extent based on findings derived from European companies business practices (Teirlinck and Spithoven, 2013; Presenza et al., 2017). European CIS data sets were found particularly useful and lead to emergence of numerous influential works, enriched our knowledge and helped shape the theoretical framework of OI concept (Laursen and Salter, 2006; Sofka and Grimpe, 2010; Spithoven, 2013). Furthermore, OI advantages were well recognized by European policymakers (European Commission, 2016). Therefore, we believe, studying the difference in the concept perception will be especially important in the European context and has the potential to contribute to theoretical debates about the OI concept as well as results into useful practical implications helping policymakers and establishing common language enabling successful industry-university collaborations.

The sample structure is presented in Table 2. The companies represent different European regions, particularly Eastern (Bosnia and Herzegovina, Croatia, Czech Republic, Hungary, Macedonia, Poland, Romania, Serbia, Slovakia, Slovenia, Turkey), Western (Austria, Belgium, France, Germany, Ireland, Luxembourg, Switzerland, The Netherlands, United Kingdom), Northern (Denmark, Estonia, Finland, Latvia, Lithuania, Sweden), and Southern (Greece, Italy, Malta, Portugal, Spain) Europe. The majority of firms belong to service industries whereas manufacturing firms account for a relatively modest share (37.8\%). In our study, we applied aggregation of high-tech industries developed by Kile and Phillips (2009) based on Global Industry Classification System (GICS). ${ }^{1}$ Consequently, the minor part of the sample (19.9\%) belongs to high-tech industries.

The sample contains firms of different sizes. However, the majority of respondents belong either to large firms (98 responses, 39\%) or SMEs (106 responses, 42\%). Microenterprises (less than 10 employees) are less widely represented (47 responses, 19\%). Such a distribution reflects the current state of OI

\footnotetext{
${ }^{1}$ https://www.msci.com/gics.
} 
adoption among firms (Brunswicker and Van de Vrande, 2014): OI is often considered to be a strategy for large firms. Although smaller companies can potentially benefit from OI (Van de Vrande et al., 2009; Vanhaverbeke et al., 2012), they often do not have the necessary resources and capabilities to engage in such activities. Consequently, the emphasis was placed on a quantitative exploration of OI practices in large firms and SMEs.

\section{Method of analysis}

Due to the binary nature of the dependent variable, we applied binary logistic regression as an estimation method. Unlike linear regression, logistic regression uses the maximum likelihood method and aims to predict not the actual values of the dependent variable, but the probability that the dependent variable belongs to the specific groups (Hair et al., 1998). In other words, we estimate the impact of the independent variables on the probability of firms to identify themselves as OI adopters. Therefore, the greater the estimation coefficient for the specific OI activity, the higher the probability that a company with a high degree of adoption of this specific activity will identify itself as an OI adopter. We conducted the statistical tests using SPSS software. To examine the hypothesis, we conduct regression analysis and analyse three models: Model 1 is a pooled model, based on the full sample, Model 2 consists of large firms, and Model 3 contains SMEs and microenterprises (due to the small sample size, we did not examine a model consisting of microenterprises only).

\section{Test for common method bias}

The cross-sectional nature of the data used in the study creates a risk of common method bias (see, e.g., Podsakoff et al., 2012). To control this, we applied Harman's one factor test. The conducted principal component factor analysis resulted in seven factors with eigenvalues greater than 1 . The scree plot (Fig. 1) confirmed the initial decision based on eigenvalues extracted. Although this criterion tends to produce larger number of factors compared to latent root criterion (see Hair et al., 1998, pp. 103-106) in our case, the difference between extracted numbers of factors is small. The variance explained by the first factor is $24.89 \%$, and the overall variance explained by seven factors solution is $65.93 \%$ which is acceptable for social science studies (Hair et al., 1998). The emergence of several factors instead of just one accounting for all variance suggests that bias due to common method is unlikely (cf. Podsakoff and Organ, 1986). Additionally, the survey design (i.e., organisation of the questionnaire, wording) was adjusted to lower the risk of common method bias (Chang et al., 2010). In particular, the respondents 


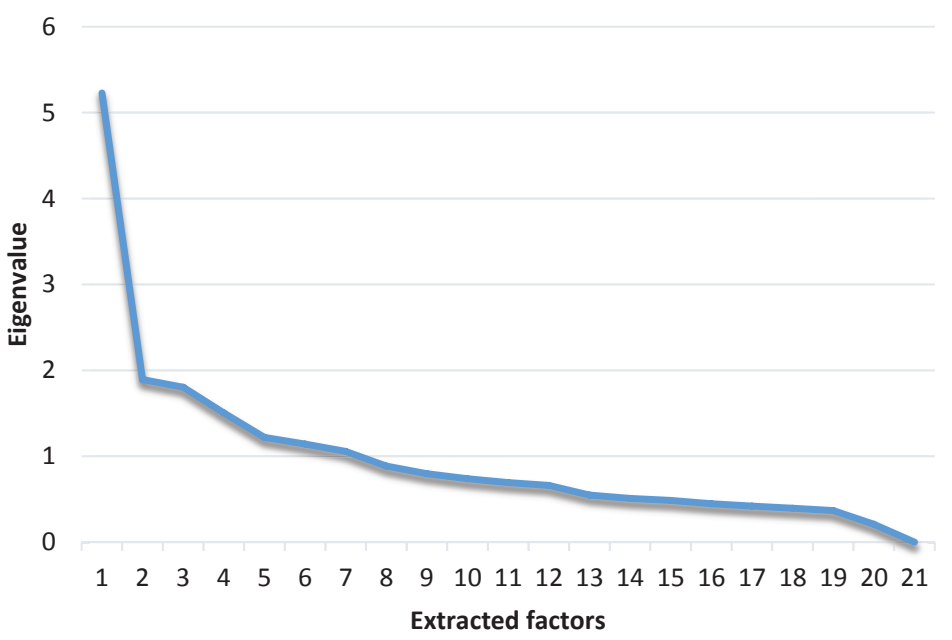

Fig. 1. Factor analysis scree plot.

were not asked to report specifically the degree of engagement with OI activities, but rather just activities without a specific mention of OI at this stage of the survey.

\section{Research Findings}

\section{The gap between OI activities adoption: de facto and self-perception}

The data reveal that the average level of OI adoption vary for different OI activities: from a maximum of $95.6 \%$ adoption (collaborative innovation with external partner and scanning for external ideas) to a minimum of $57.1 \%$ (selling unutilised/unused technologies and crowdsourcing). Cooperative and inbound modes of OI are adopted more often and more intensively than outbound modes.

Figure 2 presents the activities arranged by the percentage of companies indicating their adoption. The most intensively adopted OI activities are collaborative innovation, scanning for external ideas, using external networks, and customer co-creation in $R \& D$ projects. The least intensively adopted ones are crowdsourcing, selling unutilised/unused technologies, and IP out-licensing.

To assess the gap between self-perception of OI status and actual adoption of activities, we first analysed the descriptive statistics. We found that self-reported adoption of OI in companies is $62.2 \%$ (62.2\% of firms claim that they adopt OI). Additionally, $14.7 \%$ of firms claim that they do not adopt OI now, but plan to start doing so in the near future. At the same time, $23.1 \%$ of the respondents indicated that they do not adopt OI and do not have plans to do so (Fig. 3). Large firms have the highest level of OI adoption (67.7\%), followed by microenterprises (63.9\%), 


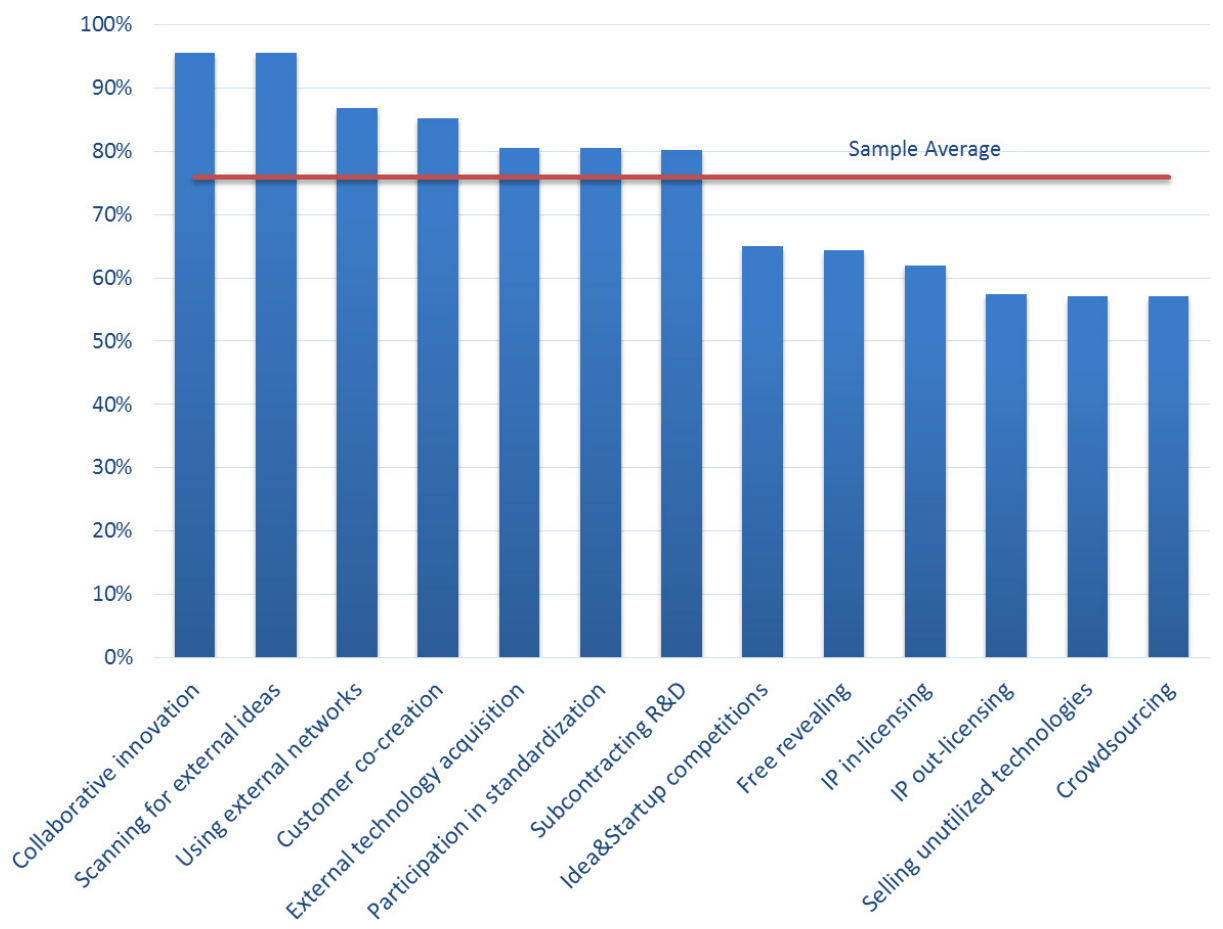

Fig. 2. Open innovation activities adoption, $\%$.

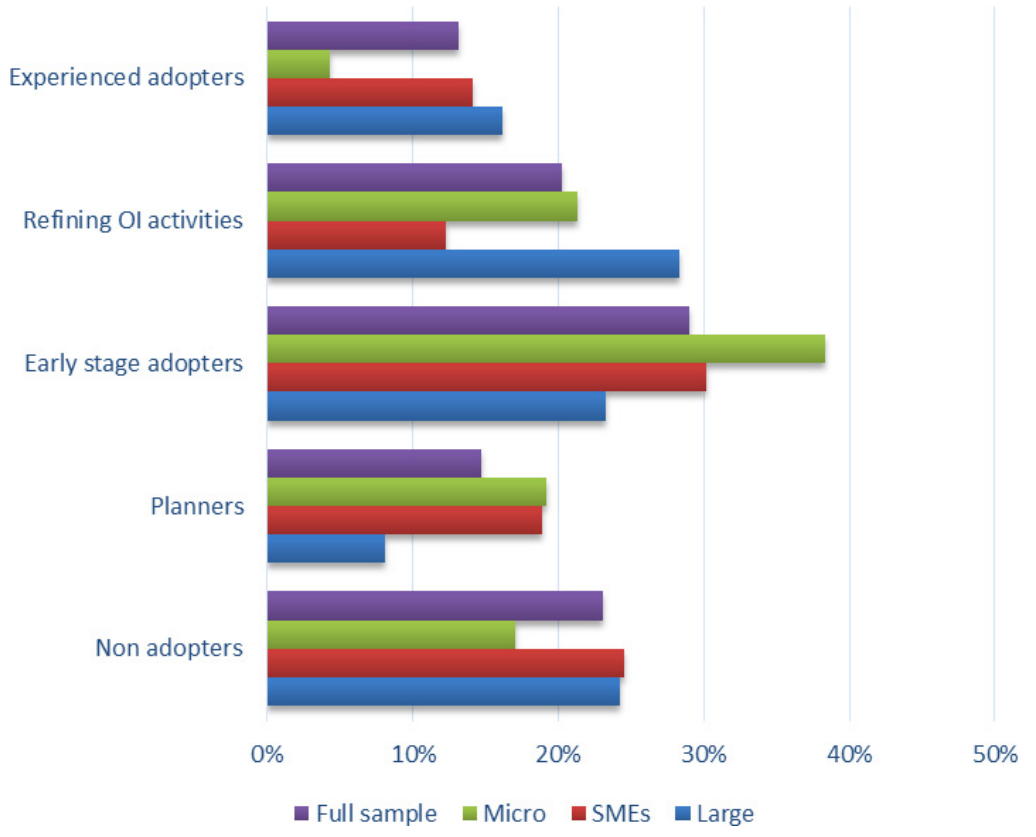

Fig. 3. Distribution of self-perception of OI adoption in sample firms. 


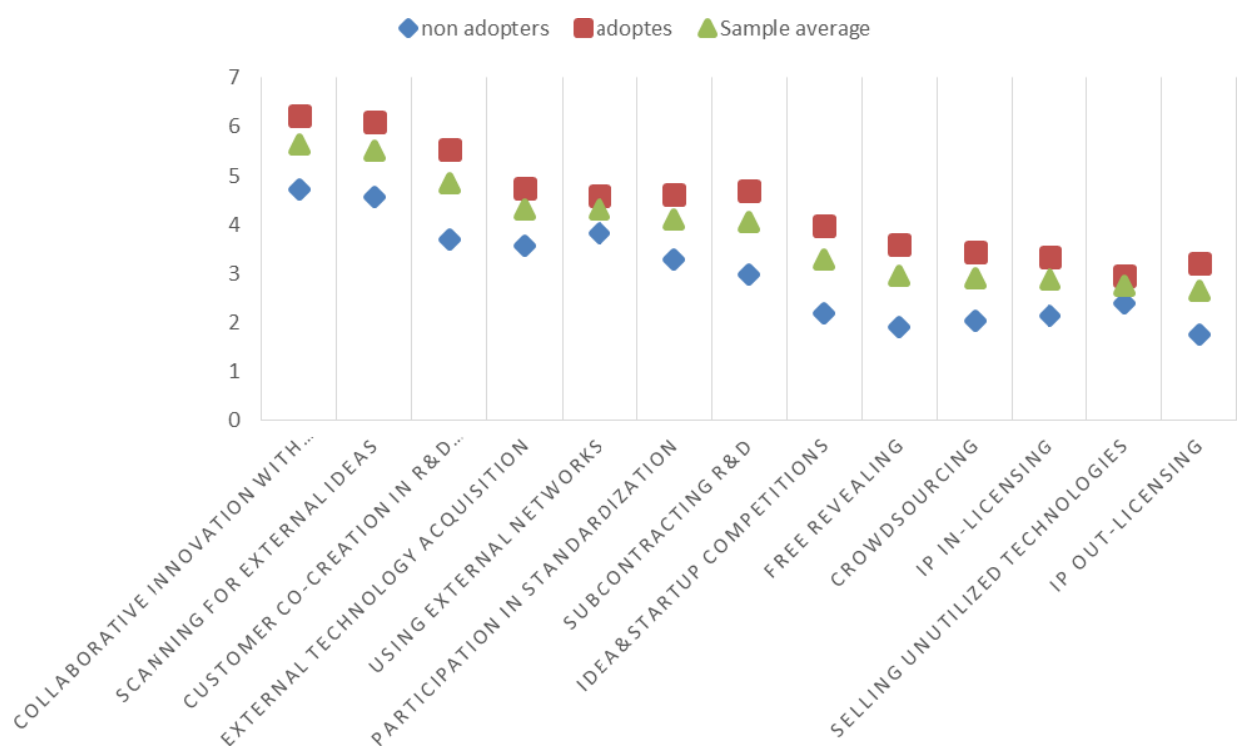

Fig. 4. Intensity of average OI activities adoption by OI adopters versus non-adopters.

whereas SMEs demonstrate the lowest degree of engagement (56.6\%). Interestingly, microenterprises and SMEs have a higher share of respondents planning to adopt $\mathrm{OI}$ in the near future, at $19.1 \%$ and $18.9 \%$, respectively (compared to large firms). This can be interpreted as a sign of the growing interest of smaller enterprises in collaboration with other parties, which is also supported by the high share of micro firms and SMEs in the early stages of OI adoption (38.3\% and $30.2 \%$, respectively).

Furthermore, we analysed the actual adoption of OI across the sample. The analysis of the adoption of 13 OI activities shows that, on average, $75.9 \%$ of the companies in our sample practice OI as per an academic perception of the concept. Our results show a $13.7 \%$ gap between the actual (de facto) open innovation adoption and companies' self-reported openness.

The gap between companies' perceptions of their OI status and the actual level of all the OI activities they adopt is illustrated in Fig. 4. Not surprisingly, companies who claim to be OI adopters perform all activities more intensively than self-proclaimed non-adopters. The difference between the two groups (adopters vs. non-adopters) is significant for all 13 activities ( $t$-test is significant at $p<0.05$ for external technology acquisition and selling unutilised/unused technologies and at $p<0.001$ for other activities). However, as shown in Fig. 4, even nonadopters still demonstrate a low to medium degree of adoption of various practices. Another interesting point is that external technology acquisition and selling unutilised/unused technologies show the least difference in the means of activity 


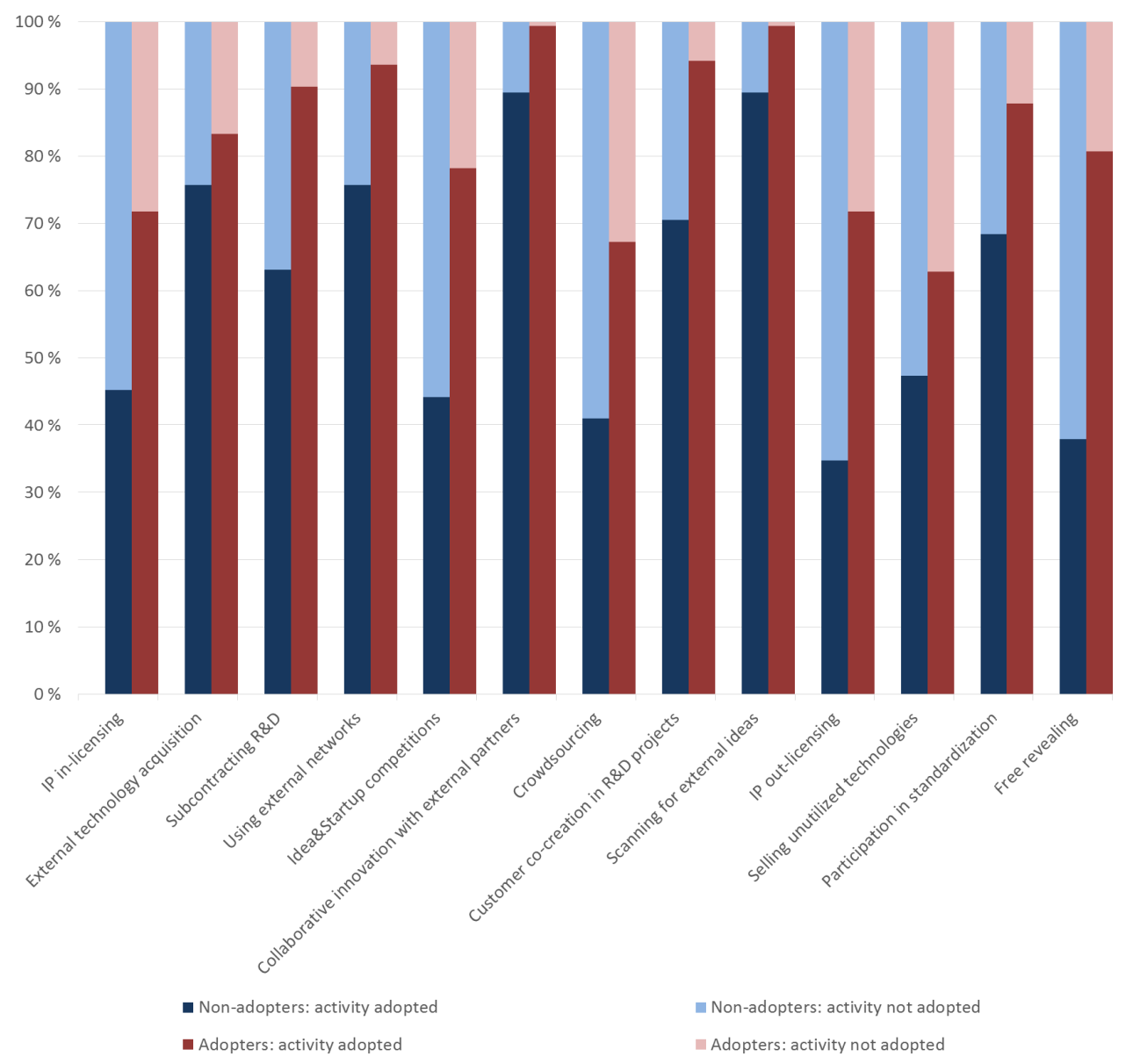

Fig. 5. Differences in activities adoption between 'OI adopters' and 'OI non-adopters'.

implementation by OI adopters vs. non-adopters. This could indicate that these particular practices are not considered to be OI activities by the companies in the sample, in contrast with the academic perception. Moreover, interestingly, the intensity of adoption of scanning for external ideas and collaborative innovation with external partners is high both for OI adopters and for non-adopters, which explains the overall popularity of these activities in the sample.

Figure 5 provides additional insight into the discovered issue. The figure enables a comparison between the share of firms who adopt a specific activity and those who do not. Each bar in Fig. 5 represents the degree of activity adoption (i.e., the proportion of those respondents who are not engaged in the specific activities, and those who adopt it to at least some degree of intensity). We also divide firms into those that identify themselves as OI adopters (reddish colour) and non-adopters (bluish colour). From this picture, we can clearly observe that a 
mismatch between perception and applied activities exists for both categories. We can identify companies whose actual degree of adoption of predefined OI activities is lower than their self-assessed status (adopters). On the other hand, there are also firms that appear to underestimate their OI status (i.e., they consider themselves to be non-adopters, whereas they are, in fact, engaged in a number of activities).

The share of such mismatches is noticeably different for different activities. For example, we observed that less than $1 \%$ of companies that report themselves to be OI adopters do not, in fact, adopt activities such as scanning for external ideas and collaborative innovation with external partners very intensively. However, for activities like selling unutilised/unused technologies, crowdsourcing, and IP in licensing, this percentage is noticeably higher (up to $37 \%$ ).

The second group of firms also demonstrates a noticeable mismatch between perception and actual activity adoption. In general, even if firms considered themselves to be non-adopters of OI, all the activities achieve noticeable engagement (the lowest share is $35 \%$ for IP out licensing and the highest is $89 \%$ for collaborative innovation with external partners and scanning for external ideas).

These findings cause concern as to whether these activities are considered by companies to be OI related. Although, at this stage, we cannot make a formal conclusion, the preliminary results indicate that the degree of engagement in specific activities is quite weakly connected to firms' perceptions about OI adoption. Therefore, in the next stage, we proceed with formal hypothesis testing.

\section{Regression analysis}

Table 3 contains descriptive statistics (means and standard deviations) of the variables and the correlation matrix. Even though the dependent variable (OI status) has significant correlation coefficients, with all proposed OI activities, the absolute value of the coefficients is quite small. The lack of a strong relationship between proposed OI activities and companies' self-evaluation provides some preliminary support for the hypothesised mismatch between business and academic understanding of OI.

To proceed with further analysis and to make a formal test of the connection between OI activities and companies' self-perception of OI, we performed regression analysis.

The regression results are presented in Table 4. Model 1 is a pooled model containing the full sample $(n=251)$, Model 2 contains only large firms $(n=98)$, and Model 3 analyses SMEs and microenterprises together $(n=153)$. All the models are significant and have sufficient predictive power (min. 79.1\%). However, not all activities provide equal impact on companies' self-perception as OI adopters. Considering Model 1, only five activities (free revealing, scanning for 


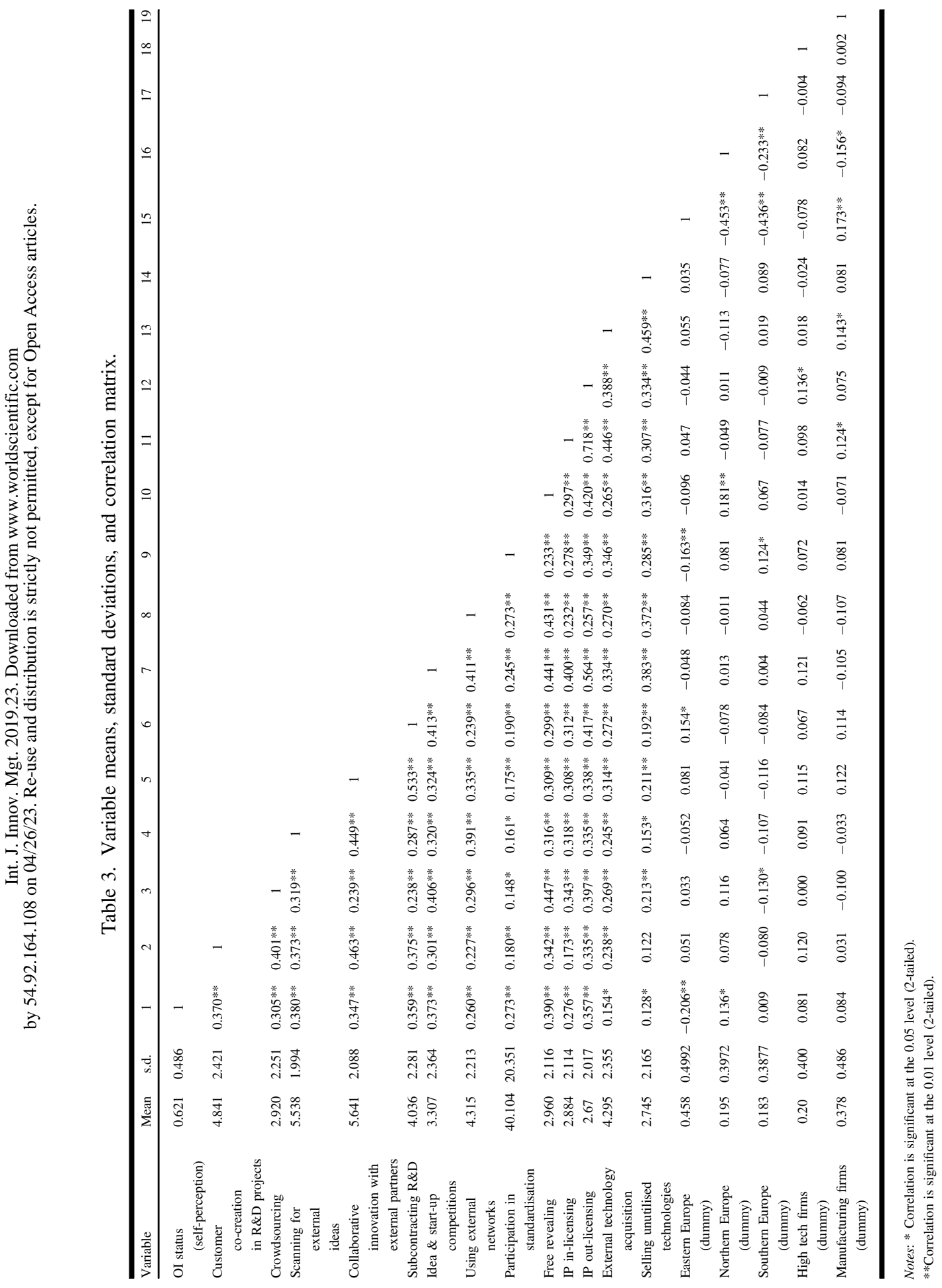


Table 4. Regression results.

\begin{tabular}{|c|c|c|c|}
\hline & Model 1 & Model 2 & Model 3 \\
\hline Customer co-creation in R\&D projects & $0.169 * *$ & -0.032 & $0.224 * * *$ \\
\hline Crowdsourcing & 0.115 & -0.181 & 0.214 \\
\hline Scanning for external ideas & $0.269 * *$ & 0.329 & $0.381 *$ \\
\hline Collaborative innovation with external partners & 0.035 & 0.074 & 0.091 \\
\hline Subcontracting R\&D & $0.217 * *$ & $0.435 * * *$ & 0.189 \\
\hline Idea \& start-up competitions & $0.253 * *$ & 0.366 & 0.234 \\
\hline Using external networks & -0.064 & 0.018 & -0.196 \\
\hline Participation in standardisation & $0.161 * * *$ & 0.216 & 0.143 \\
\hline Free revealing & $0.317 *$ & $0.957 * *$ & $0.331 * *$ \\
\hline IP in-licensing & 0.140 & -0.148 & 0.164 \\
\hline IP out-licensing & -0.021 & 0.591 & -0.103 \\
\hline External technology acquisition & $-0.171 * * *$ & 0.251 & $-0.341 * *$ \\
\hline Selling unutilised technologies & -0.103 & -0.413 & -0.010 \\
\hline Eastern Europe (dummy) & $-1.693^{*}$ & -0.171 & $-2.735^{*}$ \\
\hline Northern Europe (dummy) & -0.232 & 1.018 & -1.117 \\
\hline Southern Europe (dummy) & -0.215 & -1.154 & 0.402 \\
\hline High-tech firms (dummy) & -0.319 & 0.933 & -0.433 \\
\hline Manufacturing firms (dummy) & $0.984 * *$ & 0.163 & $1.438 * *$ \\
\hline Constant & $0.169 * *$ & -0.032 & $0.224 * * *$ \\
\hline Sample size & 251 & 98 & 153 \\
\hline -2Log-likelihood & 211.975 & 59.777 & 126.726 \\
\hline Model Chi-square statistic & $121.011^{*}$ & $64.035^{*}$ & $80.588 *$ \\
\hline Cox \& Snell R Square & 0.383 & 0.480 & 0.409 \\
\hline Nagelkerke R Square & 0.521 & 0.669 & 0.552 \\
\hline$\%$ Correct prediction & 81.7 & 87.8 & 79.1 \\
\hline Hosmer \& Lemeshow $(\operatorname{Pr}>$ ChiSq $)$ & $5.741(0.676)$ & $5.934(0.655)$ & $5.312(0.724)$ \\
\hline
\end{tabular}

Notes: Model 1: full sample; Model 2: large firms; Model 3: SMEs and microenterprises. ${ }^{*} p<0.01$; $* * p<0.05$; and $* * * p<0.1$.

external technologies, subcontracting $R \& D$, customer co-creation in $R \& D$ projects, and idea and start-up competitions) have coefficients significant at least at a 5\% level. Participation in standardization and external technologies acquisition are marginally significant $(p<0.1)$. Notably, the latter activity has a negative coefficient, meaning that increased engagement in external technologies acquisition tends to decrease chance that the company considers itself to be an OI adopter. In addition, manufacturing firms are more likely to embrace OI compared to the service sector. Looking at companies' regions, those from Eastern Europe appear less optimistic in considering their self-perceived status in OI adoption. Interestingly, other models have different sets of significant variables, meaning that, depending on firm size, various activities have an impact on company self-identification as an OI 
adopter. Similarly, for Model 1, the majority of included variables do not have a significant effect. Only one activity (free revealing) features significant coefficients (at least at a 5\% level) for all models. For some activities, the coefficients have negative signs. Moreover, in Model 3, one such activity (external technology acquisition) is significant at a 5\% level, meaning that the active adoption of such a practice by companies leads to a higher probability of self-identification as an OI nonadopter rather than as an adopter. Similarly to Model 1 (full sample), Model 3 (SMEs and microenterprises) demonstrates certain regional as well as industry differences, whereas for large companies (Model 2), these variables are not significant. Therefore, the regression results of all three models provide support for our hypothesis stating that not all practices typically considered to be OI activities by academia are assumed to be as such by business practitioners.

\section{Analysis of definitions of open innovation collected using the survey}

In order to achieve a deeper understanding of the regression results, we extended our analysis using qualitative data. The survey offered a possibility for respondents to report their own understanding of OI. We looked precisely at the answers of those companies that demonstrated a gap between self-perception and the actual intensity of adoption of OI practices. We found a few interesting examples of misinterpretation of OI (compared to the concept definition accepted by the academic community) in the qualitative data. For instance, one respondent, representing a company that, according to the survey response, is at quite a high level of OI status (4 out of 5 ) and, at the same time, is not very active in selling unused technologies ( 2 out of 7 levels of intensity), gives the following definition of OI:

\section{'Harnessing external technologies to supplement internal $R \& D$ '.}

Such a definition represents clearly and exclusively inbound OI and excludes outbound forms of it. That illustrates well the mismatch between companies' perception and factual adoption, which we found earlier for selling unused technologies.

Here is a definition of OI given by another respondent (whose company OI status is 4 , while they do not sell unused technologies at all, according to our respondent):

'Outsourcing challenges to find solutions for them'.

These findings provide us with one possible explanation of the regression results, demonstrating that understanding of OI as only inbound activities leads to constricted (self-)evaluation of the company's current OI adoption status, as some OI activities are not included for consideration (even if the company is involved in them). 


\section{Discussion}

The results prove the issue of contextual ambiguity (Dahlander and Gann, 2010) and dualism (Remneland-Wikhamn, 2013) surrounding OI concept. Particularly, our results well illustrated the fundamental issue of rigour and relevance of the management research to the real problems (van de Vrande and Man, 2011; Gulati, 2007). The results show that certain confusion exists in the understanding of the OI concept and, associated with it, OI activities (as stressed by Trott and Hartmann, 2009; Oakey, 2013), not only between academia and business, but also within these groups. However, in this study, we were aiming not only to prove this proposition, but also to try to shed light on where exactly this confusion may fall.

OI was proposed by Chesbrough more than 10 years ago as a paradigm highlighting the most possible utilisation of internal assets, as well as external ones. Our results show that the lesson of using external ideas, capabilities, and other assets (inbound OI) was learned by the studied companies, but when it comes to extracting the maximum possible benefit from internal technologies, there is still confusion in understanding it as a kind of OI practice. In particular, according to our results as per business perspective, this activity has not yet achieved a large enough weight in the whole composition of the portfolio of OI activities to have sufficient influence on defining the general level of OI adoption by a company.

At the same time, we found several activities that are well recognised by companies as OI practices. Among these is an activity, idea and start-up competitions, which was widely disseminated in the literature (and especially in business-oriented case studies) as an OI practice (Chesbrough, 2012; Huston and Sakkab, 2006; Piller and Walcher, 2006), and maybe such wide coverage in the literature contributed to increased awareness among large companies.

Subcontracting $R \& D$ is another business practice that, according to our results, is acknowledged especially by large companies as an OI activity. Even though this activity requires much less collaborative effort and involvement of internal R\&D staff than, for instance, collaborative R\&D does (Spithoven and Teirlinck, 2010), it requires sharing (opening up) the challenges with other organisations.

When it comes to sharing for free, our analysis also showed an almost unanimous view by the companies' representatives. Free revealing, without any doubt, is considered to be an OI activity by firms of all sizes. At the same time, external technologies acquisition - an activity that can be considered typical of OI demonstrates, in fact, the opposite impact on company self-positioning. This could mean that although a firm may focus on exclusively inbound OI (Van der Meer, 2007; Van de Vrande et al., 2009; Schroll and Mild, 2011; see also our results in part 4.3), the acquisition of external technologies is considered to be a self-sufficient, 
well-established process, and is not perceived as a specific OI activity (c.f. Trott and Hartmann, 2009).

When it comes to other activities defined as OI, based on the analysed literature (crowdsourcing, collaborative innovation with external partners, using external networks, IP in- and out-licensing, and selling unutilised technologies), we were unable to identify a common recognition of these practices among business representatives as kinds of OI activities, based on our data.

We also noticed certain differences between companies of various sizes (Model 2 vs. Model 3). Some activities that have a significant impact on self-assessment for large firms may not have the same effect on smaller companies, and vice versa (e.g., subcontracting $R \& D$, scanning for external technologies, external technologies acquisition). Thus, we propose a further and more in-depth analysis of separate OI activities, performed in companies of different sizes, as a direction for future research.

Manufacturing SMEs appeared more optimistic about their OI status, which may reflect a higher need for external technologies and knowledge (c.f. Brunswicker and Van de Vrande, 2014; Spithoven et al., 2013). At the same time, we found some regional differences: companies from Eastern Europe (mostly from post-Soviet countries) tended to be sceptical in evaluating their OI engagement, whereas other regions did not show a significant effect on self-identification as OI adopters. Overall, we were able to identify three groups of companies. First, those whose knowledge aligns well with the current academic understanding of OI, and, as a result, are able to identify themselves as OI adopters on the level corresponding to their actual adoption of OI activities - self-evaluation status equals the actual adoption level. Second group is those who tend to assess the intensity of their own adoption of OI activities as high, and evaluate themselves as OI adopters, but in fact do not adopt OI activities intensively - self-evaluation status is higher than the actual adoption level. Finally, third group - those who tend to underestimate their own adoption of OI activities and evaluate themselves as not adopting OI, but in fact adopt OI activities intensively — self-evaluation status is lower than the actual adoption level.

The existence of these groups illustrates, again, a mismatch that we found between self-perception and actual adoption of OI activities, between academia and practitioners.

This gap is particularly noticeable in relation to outbound activities. The reason might lie, for instance, in not-sold-here syndrome (Herzog, 2011), or in a company's strategy, size, industry (some activities could be irrelevant for certain industries), maturity of innovation practices, and market needs, as well as other institutional factors. Additionally, the reason could lie in cross-functional coordination, and subsequently in the location of the OI and cooperation function 
within the company, as well as the task and responsibility allocation for OI, and possibly other unobserved factors.

At first glance, these findings may be viewed as a support for Trott and Hartmann (2009), critics of the concept. Indeed, we found that there are companies adopting so-called OI activities without acknowledging that. At the same time, this finding goes in line with later Chesbrough and Bogers' (2014) notion that merely performing certain activities should not be considered as an exclusive indicator for OI adoption. Instead, OI activities should be analysed in the connection with firm strategy and business model.

Overall, due to the conceptual ambiguity of OI, its broadness, dualism, and the lack of standardised measures (Dahlander and Gann, 2010; Remneland-Wikhamn and Wikhamn, 2013), both practitioners and academics tend to express different interpretations of OI activities. In other words, different understanding of 'openness' in the business and academic worlds leads to different judgements about the actual level of company openness. Hence, further research on the reasons behind the discovered mismatch as well as search for the ways to omit this gap through, for instance, binding OI as a theoretical lens even more tightly with the real practical problems (van de Vrande and Man, 2011) are required.

\section{Conclusion}

In this paper, we aimed to contribute setting up the OI landscape, clarifying the drawbacks on the way to achieving rigour and relevance of 'open innovation' as a theoretical lens (Gulati, 2007). To do so, we explore the differences in the understanding of the OI concept by companies and academia in order to understand better where the concept meets with the practical problems and where still lies the mismatch between the two (van de Vrande and Man, 2011). It contributes to stimulating the debate within the innovation management community about the differences in perception of OI between these two groups, but also outlines the roots and reasons for this debate.

Our study proves that the overall actual intensity of the adoption of OI differs between companies who claim to be OI adopters, and those who claim that they do not adopt OI. However, this difference varies a lot across different activities classified as open by scholars. Additionally, there is a difference between openness measured as self-perception and openness measured as the cumulative adoption of OI activities. The latter is higher. This means that companies underestimate their level of OI adoption, and there is a lack of knowledge on OI among companies, when compared to the body of existing scientific knowledge on this phenomenon. 
We discovered that only five activities (free revealing, scanning for external technologies, subcontracting $R \& D$, customer co-creation in $R \& D$ projects, and idea and start-up competitions) have coefficients that are significant at a 5\% level and that affect companies' self-reported status in adoption of OI. However, we found that companies do not count commercialisation of unused technologies and IP out-licensing as an OI practice, while among scholars it is an acknowledged component of outbound OI (Dahlander and Gann, 2010). The data demonstrate that the other activities that belong to the OI paradigm, as per scientific research, do not yet determine the level of OI adoption as expressed by practitioners. Thus, we found our hypothesis, proposing the lack of an effect between the intensity of adoption of OI activities and a company's self-perceived status in OI, to be partly supported.

This paper contributes to conceptualising 'open innovation' by identifying and analysing the gap between the existing theoretical concepts and their perception by the business community. The process of the survey undertaken for this study has contributed to the recognition of so-called 'open innovation activities' by company managers and also to the popularisation of OI among enterprises.

The outcome of this paper - the illuminated gap between companies' and scholars perceptions of $\mathrm{OI}$ - will contribute to future qualitative and quantitative studies on conceptualising OI. Thus, the results of this paper are useful for researchers studying OI, business representatives seeking a collaborative strategy, and policymakers evaluating the level of adoption of OI activities. However, such limitations of this research as size of the sample and geographic coverage of sample need to be taken into account. The results can be influenced by the sample composition and significant share of East European companies who might be less acquainted with OI concepts and service industries who also embrace OI less actively.

Respectively, this paper has a number of implications for the broad research community studying OI or using it as a theoretical lens, for practitioners and for policymakers.

For the research community, the key message is in the need for being extremely careful when using OI concepts in the research, explaining upfront what exactly is implied by OI in the particular study, what companies' activities are included behind it. Furthermore, the researchers should also ensure rigour and relevance of their study and its findings through e.g., triangulation or member-check techniques (Krefting, 1991). The researchers are also invited to invest greater efforts in finding the links between and integrating the OI with more established and bettergrounded theoretical frameworks. One of the limitations of this study is exactly the lack of theoretical triangulation, which is due to the need for us to stay focused on the phenomenon and concept of OI. Future research may assist in overcoming this 
limitation via trying to explore the other theoretical lenses in their effort of explaining the gap in the perceptions that we have discovered and described.

For practitioners, this study outlines the broadness and dualism of the OI concept, highlighting the relevance of outbound OI activities for value creation. Our research explains how wide IS the scope of activities, WHICH have scientific reasons for being labelled as 'open innovation'. Thus, this study increases the potential relevance of the OI research for practitioners along with increasing the practitioners' understanding of it.

Our study also alerts the policymakers and attempts to make them careful when using the term 'open innovation' - avoiding senseless usage of it as a buzzword, as that has a great risk of misleading to unclear policy recommendations, which fail to equally meet the needs of business and academia as the core stakeholders on the knowledge market. The policymakers, as well as the research community, whenever using the term 'open innovation' are invited to set up clear boundaries of it, outline the practices addressed in a certain policy study and explain the value of those as well as limitations of a concrete recommendations set.

This paper creates a background for future research in the development and validation of measurement scales for OI activities and processes, and in fine-tuning the definition and methodology of OI. We see potential in the dissemination of the results of this study and the ideas of OI through business-academia workshops. This type of academia-business cooperation will help decrease the confusion in understanding OI, and will let both sides get the maximum benefits from the implementation of OI.

\section{Acknowledgement}

The data leading to this article were collected by the European Academic Network for Open Innovation (OI-Net project), which received funding from the European Union Lifelong Learning Programme under the Grant Agreement Number 20133830 (http://oi-net.eu).

\section{References}

Accenture Survey (2015). Open innovation: Collaborating successfully with small hightech firms. Accenture Institute of High Performance. Accessed June 2017, available online: https://www.accenture.com/_acnmedia/Accenture/Conversion-Assets/DotCom/ Documents/Global/PDF/Dualpub_25/Accenture-Open-Innovation-and-CollaborationExecutive-Summary-English_(secured).pdf\#zoom=50. 
AkzoNobel (2017). What is open innovation? Accessed June 2017, available online: https://www.akzonobel.com/openinnovation/what_is_open_innovation/.

Alexy, O, P Criscuolo and A Salter (2009). Does IP strategy have to cripple open innovation? MIT Sloan Management Review, 51(1), 71.

Astrazeneca (2017). Why open innovation? Accessed June 2017, available online: https:// openinnovation.astrazeneca.com/about-us.html.

Athreye, S and J Cantwell (2007). Creating competition?: Globalisation and the emergence of new technology producers. Research Policy, 36(2), 209-226.

Bayer (2017). Let's bring great ideas to life. Accessed June 2017, available online: https:// innovate.bayer.com/.

Brunswicker, S and V Van de Vrande (2014). Exploring open innovation in small and medium-sized enterprises. New Frontiers in Open Innovation, 1, 135-156.

Burcharth, A, MP Knudsen and HA Søndergaard (2014). Neither invented nor shared here: The impact and management of attitudes for the adoption of open innovation practices. Technovation, 34(3), 149-161. doi: 10.1016/j.technovation.2013.11.007.

Cassiman, B and R Veugelers (2002). R\&D cooperation and spillovers: Some empirical evidence from Belgium. American Economic Review, 92(4), 1169-1184.

Chandler, AD (1990). Scale and Scope: The Dynamics of Industrial Capitalism. Cambridge, MA: The Belknap Press.

Chang, S-J, A van Witteloostuijn and L Eden (2010). From the editors: Common method variance in international business research. Journal of International Business Studies, $41,178-184$.

Chesbrough, H (2003a). Open Innovation: The New Imperative for Creating and Profiting from Technology. Cambridge, MA: Harvard Business Review Press.

Chesbrough, H (2003b). The logic of open innovation: Managing intellectual property. California Management Review, 45, 33-58.

Chesbrough, H (2004). Managing open innovation. Research Technology Management, 47(1), 23-26.

Chesbrough, H (2006). Open Business Models: How to Thrive in the New Innovation Landscape. Boston, MA: Harvard Business Press.

Chesbrough, H (2007). Why companies should have open business models. MIT Sloan Management Review, 48(2), 22-28.

Chesbrough, H (2011). Bringing open innovation to services. MIT Sloan Management Review, 52(2), 84-90.

Chesbrough, H (2012). Why companies should have open business models. MIT Sloan Management Review, 48(2).

Chesbrough, H and S Brunswicker (2013). Managing Open Innovation in Large Firms. Berkeley, CA: Fraunhofer Verlag.

Chesbrough, $\mathrm{H}$ and M Bogers (2014). Explicating open innovation: Clarifying an emerging paradigm for understanding innovation. In H. Chesbrough, W Vanhaverbeke and J West (Eds.), New Frontiers in Open Innovation, pp. 3-28. Oxford, UK: Oxford University Press. 
Chesbrough, HW and S Brunswicker (2014). A fad or a phenomenon?: The adoption of open innovation practices in large firms. Research-Technology Management, 57(2), $16-25$.

Chesbrough, $\mathrm{H}$ and AK Crowther (2006). Beyond high tech: Early adopters of open innovation in other industries. $R \& D$ Management, 36(3), 229-236.

Clausen, TH, T Korneliussen and EL Madsen (2013). Modes of innovation, resources and their influence on product innovation: Empirical evidence from R\&D active firms in Norway. Technovation, 33(6), 225-233.

Cohen, WM and DA Levinthal (1990). Absorptive capacity: A new perspective on learning and innovation. Administrative Science Quarterly, 35(1), 128-152.

Dabrowska, J, I Fiegenbaum and A Kutvonen (2013). Mapping the perception and reality of open innovation. International Journal of Innovation Management, 17(6), 1340016.

Dahlander, L and DM Gann (2010). How open is innovation? Research Policy, 39, 699-709.

De Propris, L (2002). Types of innovation and inter-firm co-operation. Entrepreneurship \& Regional Development, 14, 337-353.

Dodgson, M, D Gann and A Salter (2006). The role of technology in the shift towards open innovation: The case of Procter \& Gamble. $R \& D$ Management, 36, 333-346.

Dushnitsky, G and T Klueter (2017). Which industries are served by online marketplaces for technology? Research Policy, 46(3), 651-666.

Ebersberger, B, C Bloch, SJ Herstad and E van de Velde (2012). Open innovation practices and their effect on innovation performance. International Journal of Innovation \& Technology Management, 9(6), 1-23.

Elmquist, M, S Ollila and A Yström (2016). Beyond intermediation: The open innovation arena as an actor enabling joint knowledge creation. International Journal of Technology Management, 72(4), 273-295.

Enkel, E, O Gassmann and H Chesbrough (2009). Open R\&D and open innovation: Exploring the phenomenon. $R \& D$ Management, 39(4), 311-316.

European Commission (2003). Commission recommendation of 6 May 2003 concerning the definition of micro, small and medium-sized enterprises. Official Journal of the European Union, 46, 36-41.

European Commission (2016). Open Innovation, Open Science and Open to the World-A Vision for Europe. Luxembourg: Publications Office of the European Union.

Freeman, C (1974). The Economics of Industrial Innovation. London: Frances Pinter.

Freeman, RE, JS Harrison, AC Wicks, BL Parmar and S De Colle (2010). Stakeholder Theory: The State of the Art. New York, USA: Cambridge University Press.

Freitas, IMB, A Geuna and F Rossi (2013). Finding the right partners: Institutional and personal modes of governance of university-industry interactions. Research Policy, 42(1), 50-62.

Gassmann, O and E Enkel (2004). Towards a theory of open innovation: Three core process archetypes. In Proc. R\&D Management Conf. Lisbon, Portugal, July 6-9.

Gassmann, O, E Enkel and $\mathrm{H}$ Chesbrough (2010). The future of open innovation. $R \& D$ Management, 40(3), 213-221. 
Gomes, E, BR Barnes and T Mahmood (2016). A 22 year review of strategic alliance research in the leading management journals. International Business Review, 25(1), $15-27$.

Granstrand, O, E Bohlin, C Oskarsson and N Sjöberg (1992). External technology acquisition in large multi-technology corporations. $R \& D$ Management, 22(2), 111-134.

Greco, M, M Grimaldi and L Cricelli (2015). Open innovation actions and innovation performance: A literature review of European empirical evidence. European Journal of Innovation Management, 18(2), 150-171.

Groen, AJ and JD Linton (2010). Is open innovation a field of study or a communication barrier to theory development? Technovation, 30(11), 554.

Gulati, R (2007). Tent poles, tribalism, and boundary spanning: The rigor-relevance debate in management research. Academy of Management Journal, 50(4), 775-782.

Hagedoorn, J (2002). Inter-firm R\&D partnerships: An overview of major trends and patterns since 1960. Research Policy, 31(4), 477-492.

Hair, JF, RE Anderson, RL Tatham and WC Black (1998). Multivariate Data Analysis. Englewood: Prentice Hall International.

Henkel, J (2006). Selective revealing in open innovation processes: The case of embedded Linux. Research Policy, 35(7), 953-969.

Herzog, P (2011). Open and Closed Innovation: Different Cultures for Different Strategies. Wiesbaden, Germany: Gabler Verlag: Springer Science \& Business Media.

Holl, A and R Rama (2012). Technology sourcing: Are biotechnology firms different? An exploratory study of the Spanish case. Science and Public Policy, 39(3), 304-317.

Hung, KP and C Chou (2013). The impact of open innovation on firm performance: The moderating effects of internal $\mathrm{R} \& \mathrm{D}$ and environmental turbulence. Technovation, 33(10), 368-380.

Huston, L and N Sakkab (2006). Connect and develop. Harvard Business Review, 84(3), 58-66.

IBM (2017). Open source projects. Accessed June 2017, available online: https://www. ibm.com/developerworks/opensource/find/projects/.

Idrissia, MO, N Amaraa and R Landrya (2012). SMEs' degree of openness: The case of manufacturing industries. Journal of Technology Management and Innovation, 7(1), $186-210$.

Kafouros, MI and N Forsans (2012). The role of open innovation in emerging economies: Do companies profit from the scientific knowledge of others? Journal of World Business, 47(3), 362-370.

Katz, R and TJ Allen (1982). Investigating the Not Invented Here (NIH) syndrome: A look at the performance, tenure, and communication patterns of $50 \mathrm{R} \& \mathrm{D}$ Project Groups. R\&D Management, 12(1), 7-20.

Kile, CO and ME Phillips (2009). Using industry classification codes to sample hightechnology firms: Analysis and recommendations. Journal of Accounting, Auditing \& Finance, 24(1), 35-58.

Kirschbaum, R (2005). Open innovation in practice. Research-Technology Management, 48(4), 24-28. 
Knudsen, MP and TB Mortensen (2011). Some immediate — but negative - effects of openness on product development performance. Technovation, 31(1), 54-64.

Köhler, C, W Sofka and C Grimpe (2012). Selective search, sectoral patterns, and the impact on product innovation performance. Research Policy, 41(8), 1344-1356.

Krefting, L (1991). Rigor in qualitative research: The assessment of trustworthiness. American Journal of Occupational Therapy, 45(3), 214-222.

Laursen, K and A Salter (2006). Open for innovation: The role of openness in explaining innovation performance among UK manufacturing firms. Strategic Management Journal, 27, 131-150.

Lichtenthaler, U (2005). External commercialization of knowledge: Review and research agenda. International Journal of Management Reviews, 7(4), 231-255.

Lichtenthaler, U (2007a). Corporate technology out-licensing: Motives and scope. World Patent Information, 29, 117-121.

Lichtenthaler, U (2007b). The drivers of technology licensing: An industry comparison. California Management Review, 49(4), 67-89.

Lichtenthaler, U (2008a). Integrated roadmaps for open innovation. Research Technology Management, May-June, 45-49.

Lichtenthaler, U (2008b). Open innovation in practice: An analysis of strategic approaches to technology transactions. IEEE Transactions on Engineering Management, 55(1), $148-157$.

Mowery, DC (2009). Plus ça change: Industrial R\&D in the "third industrial revolution". Industrial and Corporate Change, 18(1), 1-50.

Narsalay, R, J Kavathekar and D Light (2016). A hands-off approach to open innovation doesn't work. Harvard Business Review, May 3, 2016. Accessed June 2017, available online: https://hbr.org/2016/05/a-hands-off-approach-to-open-innovation-doesnt-work.

Natalicchio, A, AM Petruzzelli and AC Garavelli (2014). A literature review on markets for ideas: Emerging characteristics and unanswered questions. Technovation, 34(2), 65-76.

NineSigma (2017). What is open innovation? Accessed June 2017, available online: http:// www.ninesigma.com/open-innovation-resources/what-is-oi.

Nokia (2017). Open innovation challenge 2017. Accessed June 2017, available online: https://www.nokia.com/en_int/about-us/news-events/open-innovation-challenge.

Nonaka, I and H Takeuchi (1995). The Knowledge-Creating Company: How Japanese Companies Create the Dynamics of Innovation. New York, USA: Oxford University Press.

Oakey, RP (2013). Open innovation and its relevance to industrial research and development: The case of high-technology small firms. International Small Business Journal, 31(3), 319-336.

Pavitt, K (1984). Sectoral patterns of technical change: Towards a taxonomy and a theory. Research Policy, 13, 343-373.

P\&G Connect and Develop (2017). Open innovation in action. Accessed June 2017, available online: http://www.pgconnectdevelop.com/needs/. 
Phillips (2017). Open innovation. Accessed June 2017, Available online: http://www. philips.com/a-w/research/open-innovation.html.

Piller, FT and D Walcher (2006). Toolkits for idea competitions: A novel method to integrate users in new product development. R\&D Management, 36(3), 307-318.

Podmetina, D, I Fiegenbaum, R Teplov and E Albats (2014). Towards open innovation measurement system-a literature review. In Innovation for Sustainable Economy and Society. Paper presented at Proceedings of the 25th International Society for Professional Innovation Management Conference (Ireland), Dublin, 8-11 June.

Podsakoff, PM, SB MacKenzie and NP Podsakoff (2012). Sources of method bias in social science research and recommendations on how to control it. Annual Review of Psychology, 63, 539-569.

Podsakoff, PM and DW Organ (1986). Self-reports in organizational research: Problems and prospects. Journal of Management, 12(4), 531-544.

Polanyi, M (1966). The Tacit Dimension. Reprinted. Gloucester, Mass.: Peter Smith. Accessed August 2017. Available online: https://books.google.fi/books?id=zfsbeZHPy0C.

Popper, K (1994). The Myth of the Framework: In Defence of Science and Rationality. London and New York: Routledge.

Presenza, A, T Abbate, M Meleddu and F Cesaroni (2017). Small-and medium-scale Italian winemaking companies facing the open innovation challenge. International Small Business Journal, 35(3), 327-348.

Remneland-Wikhamn, B (2013). Two different perspectives on open innovation-libre versus control. Creativity and Innovation Management, 22(4), 375-389.

Remneland-Wikhamn, B and W Wikhamn (2011). Open innovation climate measure: The introduction of a validated scale. Creativity and Innovation Management, 20(4), 284-295.

Remneland-Wikhamn, B and W Wikhamn (2013). Structuring of the open innovation field. Journal of Technology Management \& Innovation, 8(3), 173-185.

Rohrbeck, R, K Hölzle and HG Gemünden (2009). Opening up for competitive advantage - How Deutsche Telekom creates an open innovation ecosystem. R\&D Management, 39(4), 420-430.

Samsung (2017). Open innovation. Assemblies for a new future. Accessed June 2017, available online: http://www.samsung.com/semiconductor/about-us/open-innovation/.

Sandulli, FD, J Fernandez-Menendez, A Rodriguez-Duarte and JI Lopez-Sanchez (2012). Testing the Schumpeterian hypotheses on an open innovation framework. Management Decision, 50(7), 1222-1232.

Schroll, A and A Mild (2011). Open innovation modes and the role of internal R\&D: An empirical study on open innovation adoption in Europe. European Journal of Innovation Management, 14(4), 475-495.

Sofka, W and C Grimpe (2010). Specialized search and innovation performance Evidence across Europe. R\&D Management, 40(3), 310-323.

Spithoven, A (2013). Open innovation practices and innovative performances: An international comparative perspective. International Journal of Technology Management, 62(1), 1-34. 
Spithoven, A and P Teirlinck (2010). External R\&D: Exploring the functions and qualifications of R\&D personnel. International Journal of Innovation Management, 14(6), 967-987.

Spithoven, A, W Vanhaverbeke and N Roijakkers (2013). Open innovation practices in SMEs and large enterprises. Small Business Economics, 41(3), 537-562.

Teirlinck, P and A Spithoven (2013). Research collaboration and R\&D outsourcing: Different R\&D personnel requirements in SMEs. Technovation, 33(4), 142-153.

Tether, BS and T Abdelouahid (2008). Beyond industry-university links: Sourcing knowledge for innovation from consultants, private research organisations and the public science-base. Research Policy, 37(6-7), 1079-1095.

Theyel, N (2013). Extending open innovation throughout the value chain by small and medium-sized manufacturers. International Small Business Journal, 31(3), 256-274.

Trott, P and DAP Hartmann (2009). Why 'open innovation' is old wine in new bottles. International Journal of Innovation Management, 13(4), 715-736.

Unilever (2017). Open innovation. Accessed June 2017, available online: https://www. unilever.co.uk/about/innovation/open-innovation/.

Van der Meer, H (2007). Open innovation - The Dutch treat: Challenges in thinking in business models. Creativity and Innovation Management, 16(2), 192-202.

Van de Vrande, V, JP De Jong, W Vanhaverbeke and M De Rochemont (2009). Open innovation in SMEs: Trends, motives and management challenges. Technovation, 29(6), 423-437.

Van de Vrande, V, W Vanhaverbeke and O Gassmann (2010). Broadening the scope of open innovation: Past research, current state and future directions. International Journal of Technology Management, 52(3-4), 221-235.

van de Vrande, V and AP de Man (2011). A response to "Is open innovation a field of study or a communication barrier to theory development?" Technovation, 31(4), 185-186.

Vanhaverbeke, W, I Vermeersch and S de Zutter (2012). Open innovation in SMEs: How can small companies and start-ups benefit from open innovation strategies? Research report.

Verizon (2017). Verizon open innovation is redefining what it means to create. Accessed June 2017, available online: http://verizonopeninnovation.com/.

von Hippel, E (1986). Lead users: A source of novel product concepts. Management Science, 32(7), 791-805.

West, J and M Bogers (2013). Leveraging external sources of innovation: A review of research on open innovation. Journal of Product Innovation Management, 31(4), 814-831.

West, J and S Gallagher (2006). Challenges of open innovation: The paradox of firm investment in open-source software. R\&D Management, 36(3), 319-331. 